\title{
Chemical Approaches for the Identification of PVC and PVDC in Pharmaceutical Packaging Materials
}

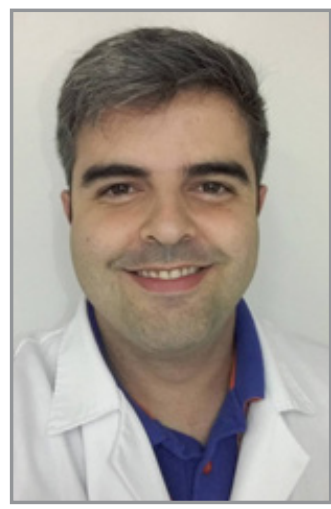

Renan M. B. Dezena*iD Preformulation Specialist Pharmaceutical Industry Rua Lousiana, 450, Chácara Campos Elíseos, Campinas, SP, Brazil

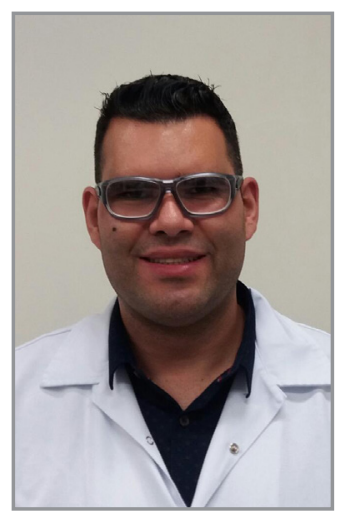

Renan C. Coelho Silva Preformulation Researcher Pharmaceutical Industry Rua Dr. Solon Fernandes, 729, Vila Rosália, Guarulhos, SP, Brazil

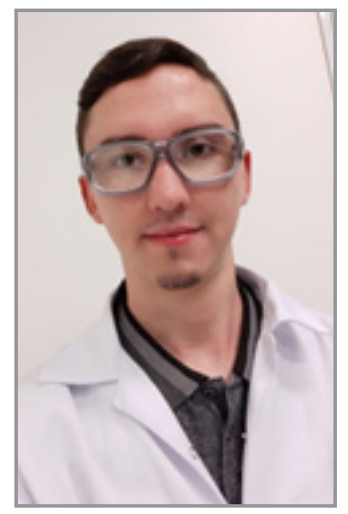

Gabriel Ferreira Luiz Analytical Dev. Analyst Pharmaceutical Industry Av. Guarulhos, 4329, Guarulhos, SP, Brazil

For the proper packaging of a drug to ensure its integrity and protection from external factors such as oxygen, moisture and light, it is essential to choose the correct packaging material [1]. Until the $19^{\text {th }}$ century, medicines were mostly stored in glass containers and cotton agglomerates, as shown in Figure 1.

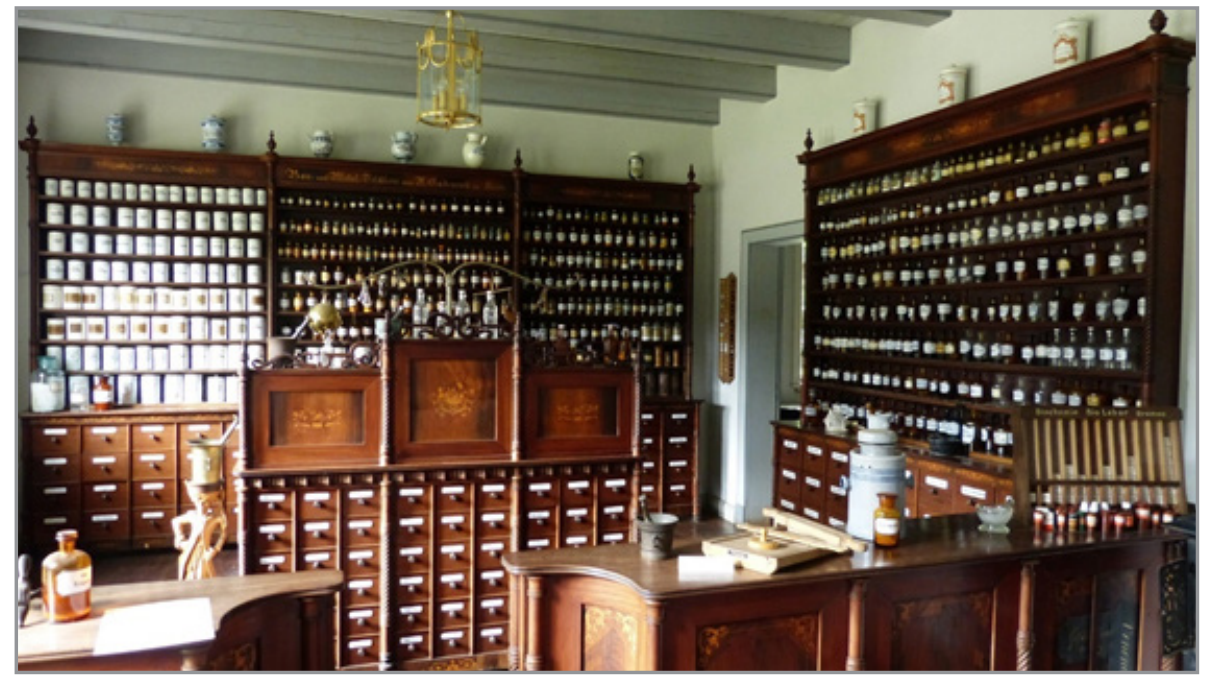

Figure 1: Drug packaging until the $19^{\text {th }}$ century [2].

In the early 1960s, with the launch of the first contraceptives, in order to increase women's adherence and facilitate their correct use, the first blister packs for drug packaging began to emerge [3]. Currently, in Europe, $85 \%$ of solid medicines are packaged in blister packs, while the blister pack is the most frequently used packaging in all pharmaceutical follow-up in Brazil [3]. In most blisters, two main polymers are used: polyvinyl chloride (PVC) and polyvinylidene chloride (PVDC) [4]. 


\section{Polyvinyl Chloride (PVC)}

This is a transparent, low cost material with high thermoforming, physical and chemical resistance, low permeability to oils, fats and aromatic substances and a low permeability index to air humidity [5]. PVC is the most commonly used material for blister packaging, being used in $80 \%$ of cases; however, among all of the materials used, this is the one that offers the least protection. Within the remaining $20 \%$ are PVC/PVDC, Aclar® and ALU/ALU [5].

The thickness of the rigid PVC film that is generally used by the pharmaceutical industries is $0.2 \mathrm{~mm}$ to $0.8 \mathrm{~mm}$. The thickness has a great influence on the light barrier property, because the higher the thickness, the lower the percentage of light that passes through the material [5].

As for the application, transparent PVC, which is the simplest type of material, has a limited barrier and will only be used for more stable drugs in the presence of moisture or light, such as paracetamol and cotrimoxazole, although some manufacturers can add barrier enhancing additives such as UV light absorbers [5].

In the manufacture of PVC, there is a release of toxins during its combustion; this has led to its replacement by polypropylene (PP) for blister packs in Europe. Polyethylene terephthalate (PET) and polystyrene (PS) can replace PVC; however, their high moisture permeability compared to PVC restricts their use [5]. PP has a high shrinkage rate during thermoforming, which makes it one of the most difficult to shape. PP is most often used for suppository packaging [5]. In addition, it is unsuitable for the packaging of photosensitive pharmaceutical products, as it has a transmittance of up to $80 \%$ between 300 and $400 \mathrm{~nm}$, differing from that which is currently required in Pharmacopoeia, a transmittance of at most $25 \%$ and $20 \%$, respectively, within a wavelength range between 290 and $450 \mathrm{~nm}$ [5].

\section{Polyvinylidene Chloride (PVDC)}

PVDC is used in PVC-laminated or coated packaging, reducing the permeability of PVC to oxygen and moisture by 5-10 times [5]. Moldable film is usually colorless and transparent, but may be darkened to protect light-sensitive products. PVDC cannot be used as a sole material due to its relatively high cost and mechanical properties. The best properties are obtained by combining PVDC with a PVC base coat, which is used for products that are not very sensitive to external factors and have a long shelf life, such as capsules or multivitamin tablets [5].

Different blister formats are shown in Figure 2.

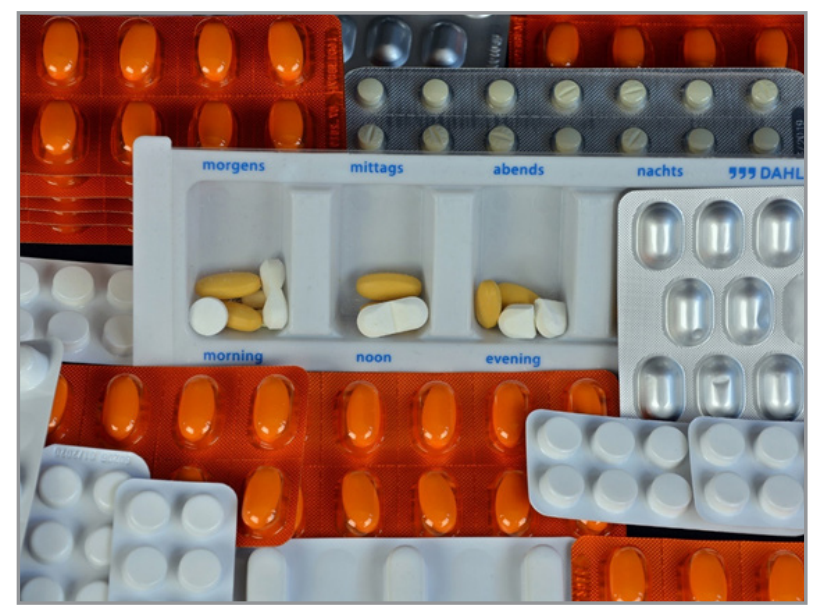

Figure 2: Drug blisters [6].

It is important to correctly identify the materials used for the construction of the blister in order to ensure its quality and efficiency in the protection of the drug. A safe and effective way to make this identification is through a chemical indicator solution [7]. 
This chemical indicator solution should be prepared as follows:
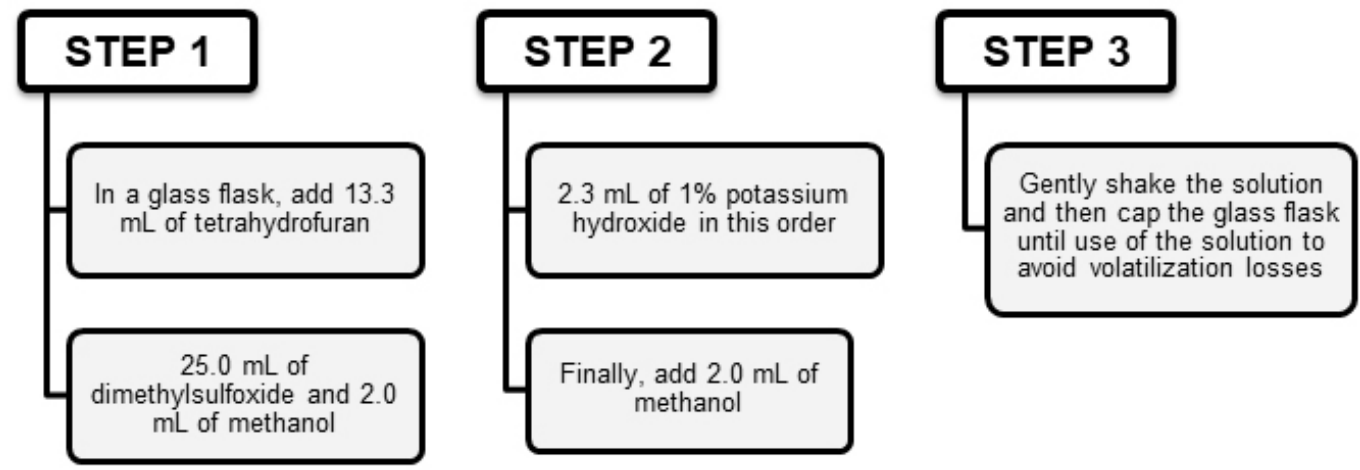

After preparing the chemical indicator solution, the PVC and/or PVDC samples should be prepared for identification by cutting a piece that is approximately $5 \mathrm{~cm}$ wide and $5 \mathrm{~cm}$ long; in fact, a bubble is sufficient, as shown in Figure 4. The identification solution should be added throughout the surface of the material to be identified and then left for about 30 seconds for the solution to change color. Initially, the solution is colorless, but will turn brown on contact with PVC, and black on contact with PVDC, as shown in Figures 3 and $4[7,8]$.

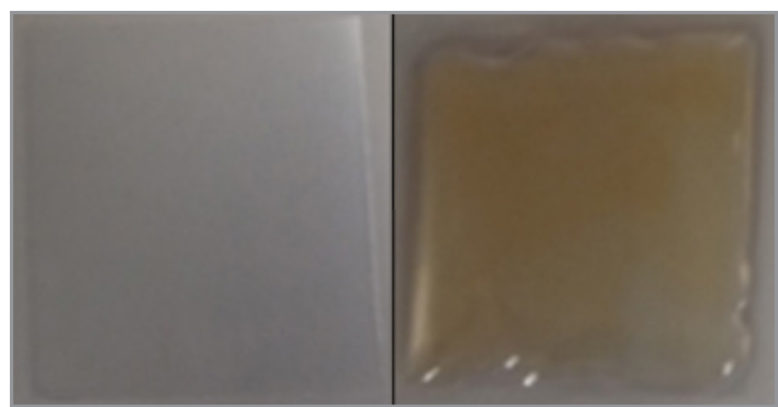

Figure 3. PVC blister. Left: before addition of the identification solution; Right: 30 seconds after addition of the identification solution.

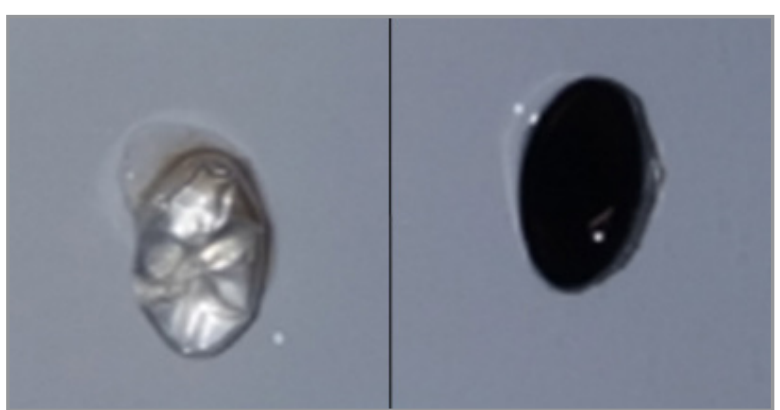

Figure 4. PVDC blister. Left: before addition of the identification solution; Right: 30 seconds after addition of the identification solution.

It is important to photograph the samples before and after adding the identification solution for future comparisons of color changes. In the case of drug blisters, it is common to use PVC on one side and PVDC on the other; therefore, it is also important to identify both the inner and outer faces of the blister.

\section{REFERENCES}

1. Zadbuke, N.; Shahi, S.; Gulecha, B.; Padalkar, A.; Thube, M. J Pharm Bioallied Sci., 2013, 5 (2), pp 98-110 (http://dx.doi.org/10.4103/0975-7406.111820).

2. https://pixabay.com/photos/molfsee-open-air-museum-building-851316/ [Accessed Nov. 6, 2019$].$

3. https://www.montesino.com/resources/early-blister-packaging/ [Accessed November 6, 2019].

4. Wypych, G. Handbook of Polymers. ChemTec Publishing, Toronto, 2016, pp 618-629.

5. Pereira, D. A. C.; Ferreira, L. A. Visao Acad., 2016, 17 (3), pp 91-100 (http://dx.doi.org/10.5380/acd.v17i3.48422).

6. https://pixabay.com/photos/tablets-medical-health-ill-pills-2148890/ [Accessed Nov. 6, 2019].

7. Urzendowski, I. R.; Pechak, D. G. Food Struct., 1992, 11 (4) pp 301-314.

8. http://www.celplast.com/packaging-insight/top-tips-for-checking-treat-side-of-substrates/ [Accessed November 6, 2019]. 